\title{
Neural Stem Cell Transplantation as a Therapeutic Approach for Treating Lysosomal Storage Diseases
}

\author{
Lamya S. Shihabuddin • Seng H. Cheng
}

Published online: 9 September 2011

(C) The American Society for Experimental NeuroTherapeutics, Inc. 2011

\begin{abstract}
Treating the central nervous system manifestations of subjects with neuropathic lysosomal storage diseases remains a major technical challenge. This is because of the low efficiency by which lysosomal enzymes in systemic circulation are able to traverse the blood brain barrier into the central nervous system. Intracranial transplantation of neural stems cells genetically modified to overexpress the respective deficient enzymes represents a potential approach to addressing this group of diseases. The unique properties of neural stem cells and progenitor cells, such as their ability to migrate to distal sites, differentiate into various cell types and integrate within the host brain without disrupting normal function, making them particularly attractive therapeutic agents. In addition, neural stem cells are amenable to ex vivo propagation and modification by gene transfer vectors. In this regard, transplanted cells can serve not only as a source of lysosomal enzymes but also as a means to potentially repair the injured brain by replenishing the organ with healthy cells and effecting the release of neuroprotective factors. This review discusses some of the well-characterized neural stem cell types and their possible use in treating neuropathic lysosomal storage diseases such as the Niemann Pick A disease.
\end{abstract}

Keywords Neural stem cells · Neural progenitor cells · Cell transplantation · Lysosomal storage diseases · Niemann Pick A disease

Electronic supplementary material The online version of this article (doi:10.1007/s13311-011-0067-8) contains supplementary material, which is available to authorized users.

L. S. Shihabuddin $(\bowtie) \cdot$ S. H. Cheng

Genzyme Corporation,

49 New York Avenue,

Framingham, MA 01701-9322, USA

e-mail: Lamya.shihabuddin@genzyme.com

\section{Introduction}

During the past decade, the potential of stem cell transplantation as a therapeutic modality for neurodegenerative and neurometabolic diseases has gained significantly increased interest. Potential applications of this technology include its use as a cell replacement or augmentation therapy and as a source of cellular factors that might be deficient in the host or trophic factors that promote survival and repair of the central nervous system (CNS) of the host. However, given the complexity of the cellular organization of the CNS, particularly in diseased states, their deployment as cellular vectors to prevent or ameliorate neurological disorders likely represents a more tenable short-term goal than that of a vehicle for cell replacement and regrowth of damaged circuitry.

Lysosomal storage diseases (LSDs) represent a group of more than 50 metabolic disorders caused by mutations in genes encoding catabolic enzymes involved in the normal degradation of macromolecules within the lysosomes [1]. A deficiency in the activity of 1 or more of these lysosomal enzymes leads to the progressive accumulation of uncatabolized substrates and consequent cellular dysfunction and organ failure $[1,2]$. Testing of cellular therapies in several animal models of LSDs has shown that a combination of gene and stem cell therapy might represent an optimal therapeutic paradigm. Further research is underway to bridge the preclinical development path to clinical studies in humans. Here, we discuss select examples of preclinical studies that highlight both the promise and challenges of this technology platform to treating LSDs.

\section{Sources of Neural Stem Cells and Progenitor Cells}

Neural stem cells (NSCs) have demonstrated the potential as a therapeutic modality for the repair of a number of CNS 
disorders. NSCs derived from either the developing or adult CNS are a heterogeneous population of mitotically active, self-renewing, and multipotent cells [3, 4]. They exhibit select cardinal features, such as the ability for unlimited self-renewal via asymmetric cell division, indefinite ability to proliferate in response to mitogens, and multipotency for the different neuroectodermal lineages of the CNS [5-7]. Self-renewal is defined as the capacity of a cellular clone to generate new stem cells with identical properties for multiple generations, a characteristic that can be prompted by the provision of mitogens [5]. Multipotency refers to the capacity of clones derived from single founder stem cells to differentiate and generate multiple cell types of a particular germ layer. Neural progenitor cells (NPCs) derived form the CNS are also multipotent cells, capable of giving rise to neurons, astrocytes, and oligodendrocytes, but contrary to NSCs the NPCs have limited self-renewing capacity [5, 7]. NPCs are a step further along the path of differentiation than NSCs. Different, but well-defined procedures have been developed for the isolation, safe expansion, and maintenance of these cells in chemically defined media for several years $[8,9]$.

The ideal donor cells for use in transplantation studies should be easy to isolate and produce in large numbers. They also need to be competent in effecting cellular or molecular replacement in the CNS without causing a deleterious outcome (e.g., tumor growth). For the past several years, protocols that allow for the generation of a large number of NPCs in vitro have been established, thereby supporting the concept that these cells might represent a renewable source of uncommitted, ready-to-use cells for transplantation purposes [10]. Neural cells with stem cell properties have been isolated from fetal [11, 12], neonatal [13, 14], and adult [13] human brains, as well as rodent CNS using both epigenetic (with the mitogens epidermal growth factor [15] or basic fibroblast growth factor [16-18]) and genetic (with the reversible oncogenes $\mathrm{v}-\mathrm{Myc}$ or large $\mathrm{T}$ antigen $[19,20]$ ) strategies. NPCs can also be isolated from human fetal and adult tissue by enzymatic dissociation followed by expansion in the presence of specific growth factors rich and serumdeficient media. Additionally, fluorescence activated cell sorting and surface antigen-based cell sorting can be used to facilitate purification of the cells [11-14]. Adult-derived NSCs and NPCs avoid the ethical concerns associated with fetal-derived cells. However, NSCs are more difficult to isolate from brain biopsies or autopsy samples [13, 14]. Additionally, human adult NSCs and NPCs do not show telomerase activity and have limited proliferation capacity following serial passaging in vitro [21]. Although NPCs from different species respond positively to growth factors, their growth properties can differ depending on the conditions being used [22]. NSCs can be expanded either as adherent cultures [5] or spherical aggregates termed "neurospheres"
[15]. In serum-free cultures supplemented with epidermal growth factor and/or fibroblast growth factor-2 multipotent NPCs are able to proliferate indefinitely. Moreover, these clones spontaneously differentiate into postmitotic CNS daughter cells (such as neurons, astrocytes, or oligodendrocytes) at withdrawal of the growth factors $[5,6,10]$. Brain-derived NPCs have received the most attention as a source of cells for neural cell replacement, and they have been widely used for proof-ofconcept studies in animal models of diseases [23, 24]. However, the limited availability of donors and the difficulty associated with expanding cells derived from postmortem adult tissue coupled with the concern of potential immune rejection of transplanted cells provide challenges for their use as a source of donor cells for therapeutic applications.

NPCs have also been isolated from pluripotent human embryonic stem cells (ESCs) [25]. ESCs derived from the inner cell mass of blastocyst stage embryos exhibit 2 unique characteristics: 1) an indefinite capacity for selfrenewal and 2) pluripotency. ESCs can indefinitely divide into the undifferentiated state, and when exposed to certain conditions ESCs are able to differentiate into any cell type including neural progenitors; thus, ESCs are considered truly pluripotent [25]. Improvements to methods to scale production of the ESCs to numbers necessary for transplantation have been recently described. Feeder independent growth of human ESCs (using protein components solely derived from recombinant sources or purified from human material) has been achieved [26, 27], as has the propagation (through continuous asymmetric cell division) of ESC-derived neural stem cells without the accompanying differentiation [28]. These ESC-derived NPCs have been used in multiple animal studies. The transplanted cells have been shown to successfully be integrated and differentiated in a region-specific manner into neurons, astrocytes, and oligodendrocytes [29, 30]. Although, ESC-derived NPCs can potentially provide a limitless source of donor cells, several challenges remain a concern regarding the clinic use of these cells. First, as with NPCs and other allogenic transplants, there are concerns of immunorejection and the need of immunosuppression. Second, the presence of undifferentiated cells and increased risk of tumorigenesis. Protocols to avoid the formation of teratocarcinomas following transplantation of ESCs or ESC-derived NPCs are still being developed [31]. Recently, a clinical trial aimed at repairing traumatic spinal cord injury using oligodendrocyte precursors derived from human ESCs received authorization from the regulatory agency [32].

Furthermore, the derivation of human ESCs remains controversial on ethical grounds, prompting the search for alternative sources of NSCs. Recently, efforts in somatic cell reprogramming culminated in the generation of a new class of pluripotent cells, and the so-called induced pluripotent stem cells (iPSCs) was reported. These iPSCs 
are generated from adult somatic cells by the introduction of embryogenesis-related genes [33-35]. Adult fibroblasts obtained from skin biopsies, as well as adult somatic cells from other sources, can be converted to iPSCs by the overexpression of the transcription factors POU5F1 and $S O X 2$. IPSCs are similar to ESCs and can be differentiated into NSCs in vitro using similar techniques and serve as a source of cells for different tissues. Pluripotent ESCs and iPSCs can be expanded indefinitely in culture because they express telomerase, which prevents chromosome aging [36]. Patient-derived iPSCs have the potential to avoid ethical problems and innate immune rejection associated with ESC-derived cell therapeutics. All of these sources of stem cells (summarized in Fig. 1) are currently subjects of active investigation to characterize their survival, migratory capacity, and efficacy in providing functional benefit in various models of neurodegenerative and neurometabolic diseases, and the feasibility of translating the preclinical data to clinical applications. Furthermore, recent studies have described new methods for somatic cell reprogramming to generate lineage-specific cells for tissue replacement. Kim et al. [37] demonstrates successful transdifferentiation of somatic cells into proliferating NPCs, bypassing the intermediate pluripotent stage. Alternatively, transdetermination is the in vivo cellular reprogramming of a stem or progenitor cell into a related lineage using a single transcription factor [38]. The therapeutic potential of these new trends in cellular reprogramming remain to be evaluated. Other sources of non-CNS-derived somatic multipotent stem cells that are capable of terminal neural differentiation include bone marrow stem cells [39], mesenchymal stem cells (MSCs) derived from bone marrow or blood [40, 41], placental cord blood stem cells [42, 43], amniotic fluid [44], skin stem cells [45], and adipose tissue stem cells [46].

\section{Neural Cell-Mediated Therapy of Lysosomal Storage Diseases}

The ability of human NPCs to participate in brain repair has recently been demonstrated in preclinical studies. Transplantation of human NPCs into rodent brains led to their

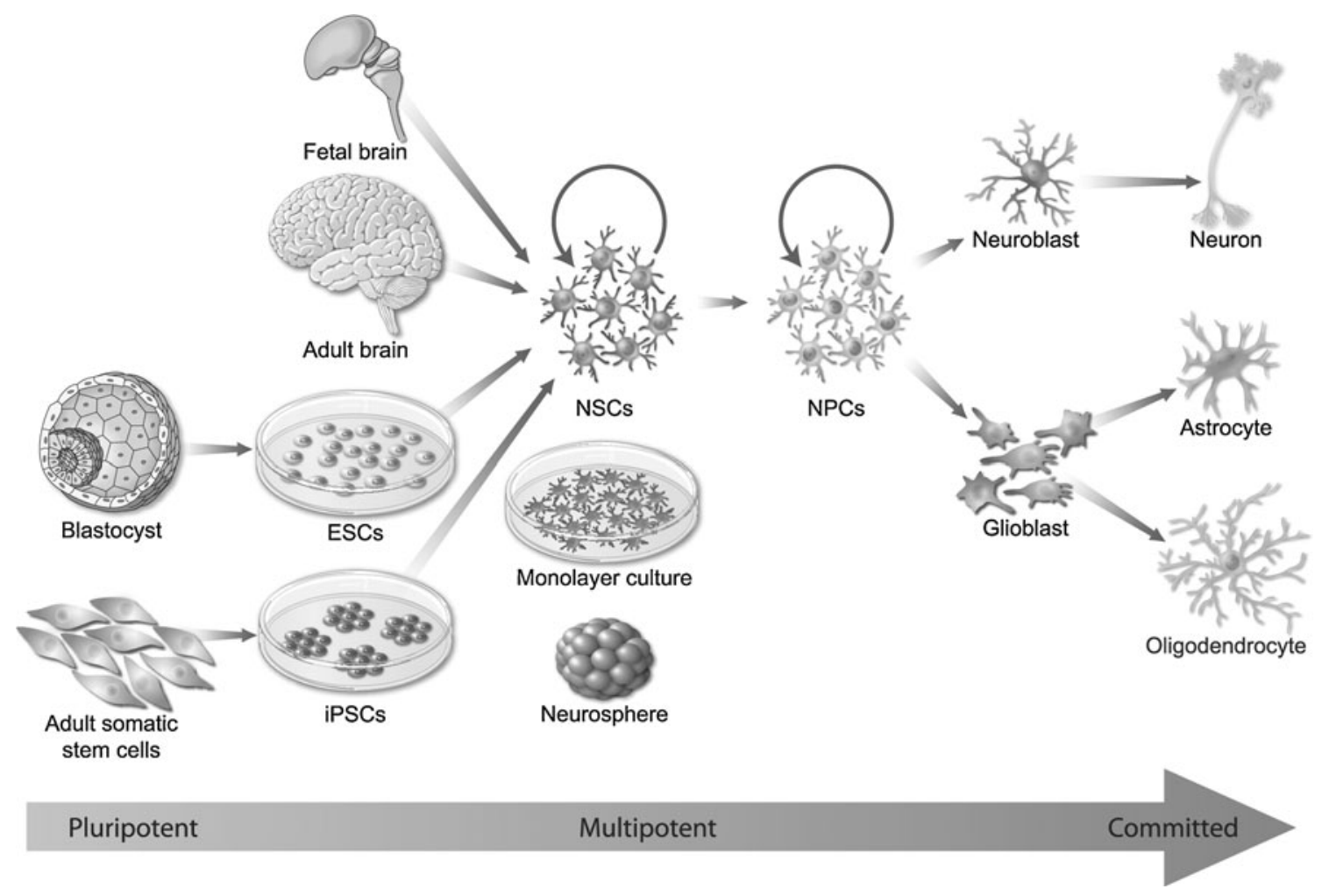

Fig. 1 Sources of neural stem cells (NSCs). Self-renewing and multipotent NSCs for transplantation can be isolated from a variety of human cell and tissue sources and expanded as attached "monolayers" or free floating "neurospheres." The 3 main sources of these cells are: 1) endogenous central nervous system (CNS)-derived NSCs from fetal or adult donor brain or spinal cord tissue, 2) embryonic stem cell (ESC)-derived NSCs, and 3) adult somatic tissue-derived NSCs generated by induced pluripotent stem cell (iPSCs) technology. There are several extents of multipotency; stem cells that possess the capacity to generate lineages derived from all 3 primary germ layers are pluripotent (e.g., ESCs), and tissue-derived stem cells are more restricted multipotent cells that can differentiate to give rise to multiple cell types within a particular germ layer (e.g., NSCs and neural progenitor cells [NPCs]). Neuroblasts and glioblasts are further restricted in the differentiation process and are committed to a specific cell lineage 
subsequent migration along appropriate tracts and differentiation into neurons and glia in a region-specific manner [19, 24, 47, 48]. As such, NPCs can be considered a viable source of donor cells to achieve cell replacement and effect circuit repair in the CNS. However, depending on the nature of the disease, the deployment of NPCs as cellular vectors to provide trophic support of the host tissue or augment the levels of a deficient enzyme might be equally beneficial. In this regard, hereditary diseases, such as the LSDs, are appropriate candidates for cell-based therapy.

\section{Lysosomal Storage Diseases}

Lysosomal storage diseases are a diverse group of metabolic disorders that are typically inherited in an autosomal recessive manner [49]. As an aggregate, LSDs affect approximately 1 in 7700 births with the most affected individuals showing a diffuse CNS involvement [49]. LSDs are caused by a deficiency in 1 or more of the approximately 50 lysosomal enzymes described to date. This loss in enzyme activity leads to progressive accumulation of undegraded substrates in the lysosomes resulting in distension of the organelle, subsequent cellular malfunction, and clinical disease [2]. Although lysosomal enzymes are constitutively expressed in all cell types, the extent of substrate accumulation for a particular LSD depends on the rate of production of that substrate in the different cells. Consequently, some LSDs have primarily a CNS presentation, whereas others have little or no CNS involvement. Treatments such as systemic enzyme replacement therapy and substrate reduction therapy have been shown to be effective for some LSDs, such as Gaucher, Fabry, Pompe, Mucopolysaccharidosis (MPS) type I, II, and VI diseases [1]. Although systemically delivered recombinant enzymes are effective at correcting the visceral disease, they do not address the CNS manifestations because of their inability to traverse the BBB into the brain [50]. Intracranial injections of recombinant lysosomal enzymes, viral vectors or stem cells encoding the deficient enzymes, or systemic infusions of modified enzymes that can transverse the BBB are being evaluated as potential approaches to address this limitation. This review is focused on neural cell-based strategies for treating the neuropathic LSDs.

\section{Cross-Correction}

The rationale for a cell-based therapeutic for the LSDs is predicated on the notion that delivery of a small number of cells will suffice to correct large regions of the brain. This supposition is borne of demonstrations that lysosomal enzymes are capable of undergoing diffusion and facilitating cross-correction of adjacent cells by virtue of the mannose 6phosphate receptor present in most cell types in the CNS. Moreover, based on a large number of studies, it is anticipated that a low level reconstitution of enzyme activity in the cells will be therapeutic [51-53]. However, invasive intracranial delivery of the cells will be required to bypass the BBB [54, 55]. To maximize the expression and secretion of lysosomal enzymes, cells can be genetically modified by ex-vivo transduction of cells using well-established gene transfer methodologies prior to their transplantation. This strategy has been evaluated and shown to be effective in treating several mouse models of LSDs with neuropathic disease [56-59]. The first demonstration of the therapeutic potential of NSCs came from studies in MPS VII mice using NPCs engineered to overexpress $\beta$-glucuronidase (enzyme deficient in MPS VII disease) into the cerebral ventricles of mice. Transplantation of the gene-modified NPCs led to engraftment and differentiation of the donor cells, secretion of the enzyme, and cross-correction of adjacent cells [60]. Similar findings were achieved using genetically modified human NPCs in this mouse model [56, 57]. Intracranial injections of gene-modified multipotent NPCs also resulted in a broad distribution of $\beta$-hexosaminidase, the enzyme deficient in Tay-Sachs disease, in the brains of transplanted mice [61]. Transplantation of unmodified murine NSCs into neonatal Sandhoff diseased (another LSD) mice was also effective in delaying disease onset, reducing storage pathology, and extending longevity [62]. These observations were extended to unmodified human NSCs isolated from the CNS and embryonic stem cells [60]. Perhaps a more clinical relevance was the demonstration of efficacy with murine-derived NSCs in adult, symptomatic Sandhoff mice [63].

\section{Cell-Mediated Gene Therapy}

An effective stem cell-based therapy for LSDs with CNS disease requires the cells to migrate from the sites of administration to broad regions of the brain parenchyma, and importantly to act secondarily as depots for the production and secretion of lysosomal enzymes. The latter will allow for correction of adjacent diseased host cells via mannose 6-phosphate receptor-mediated endocytosis to reduce storage accumulation, normalize lysosomal function, and prevent neurodegeneration. For the cells to act as effective depots for the production of lysosomal enzymes, appropriate levels of enzyme synthesis and secretion need to be demonstrated in preclinical studies. In some animal models of LSDs with neurometabolic diseases, such as Sandhoff $[62,63]$ and infantile neuronal ceroid lipofuscinosis [64], immortalized NSCs that had been isolated directly from human CNS or derived 
secondarily from ESCs, are able to secrete appropriate levels of the deficient enzymes. In contrast, in Niemann Pick A disease, adult mouse-derived NPCs needed to be modified by ex-vivo gene transduction before they were able to secrete therapeutic amounts of acid sphingomyelinase (SMPD1), the deficient enzyme [58]. NPCs were transplanted into the striatum, hippocampus, or thalamus of the mouse model of Niemann Pick A $(100,000$ cells/ site). The survival, differentiation, and distribution characteristics of gene-modified (to express SMPD1) and unmodified NPCs were similar. However, lysosomal storage pathology was only reduced in areas that had received transplants of gene-modified NPCs (Fig. 2). Transplantation of unmodified NPCs had no obvious impact on the degree of storage pathology. Sphingomyelin, the primary substrate that accumulates in NiemannPick A disease, has a strong affinity for cholesterol, which leads to sequestration of amounts of this lipid in the lysosomes of Niemann-Pick A disease mice and human patients [65-67]. Filipin staining (an autofluorescent molecule that binds to cholesterol complexes $[65,68]$ ) demonstrated low levels of fluorescent deposits were evident in the CA1 pyramidal cell layer (Fig. 2d), granular cell layer, and CA4 pyramidal cell layer of the hippocampus (Fig. 2f) that received gene-modified NPCs. However, more extensive fluorescent staining was observed in corresponding sections that received unmodified NPCs, suggesting a lesser reduction in cholesterol levels (Fig. 2c,


Fig. 2 Survival and efficacy of neural progenitor cells (NPCs) following transplantation (100,000 cells per site) into the brains of a mouse model of Niemann Pick A disease. Regional clearance of cholesterol deposits in the hippocampus 4 weeks after bilateral transplantation of acid sphingomyelinase (SMPD1)-transduced or nontransduced NPCs. (a, b) Coronal view of the adult mouse hippocampus shows the comparable survival and dispersion of transplanted (a) unmodified NPCs or (b) modified NPCs. Coronal section of $(\mathbf{c}, \mathbf{d})$ pyramidal CA1 and the dentate gyrus, and (e, f) CA4

pyramidal cell layer showing the marked reduction of fluorescent deposits visualized by filipin staining on sections that received $(\mathbf{d}, \mathbf{f})$ gene-modified cells vs (c, e) unmodified cells. Insets are higher magnification views showing more clearly the cytoplasmic clearance of fluorescent deposits from the (d) CA1 pyramidal neurons and (f) granular neurons on sections treated with $(\mathbf{c}, \mathbf{e})$ gene-modified $v s$ unmodified cells. (a, b) Scale bars $=200 \mu \mathrm{m}$; (c-f) scale bars = $100 \mu \mathrm{m}$; insets scale bars $=10 \mu \mathrm{m}$. (Adapted from Shihabuddin et al. [58]) 
e). The areas of clearance tightly overlapped with the regional migration of gene-modified NPCs as viewed in adjacent sections (Fig. 2a, b). Immunostaining for lysenin, a sphingomyelin-specific binding protein [69], was also used to assess sphingomyelin storage, as shown the amount of lysenin-sphingomyelin staining, which was only reduced in the areas that received transplants of gene-modified NPCs (Fig. 3b) and not in those treated with nontransduced NPCs (Fig. 3a). Interestingly, levels of SMPD1 expression needed for efficacy appeared to be very low suggesting that only a small amount of secreted enzyme is required to cross correct the storage pathology of adjacent cells (Fig. 4). This finding is consistent with those reported for other storage diseases, in which only a fraction of normal levels of enzyme was required to decrease the storage pathology and severity of the disease [70]. However, the number or proportion of enzymeexpressing cells required to achieve local correction of enzymatic activity and substrate clearance in any storage disorder probably needs to be determined for each disease target. Also critical to the approach of cell-mediated gene therapy for LSDs is the ability of these cells to extensively migrate into the brain parenchyma. It is worth noting that these mouse NPCs did not migrate as widely as immortalized murine and human NSCs following transplantation into neonatal Niemann-Pick A disease mice [71]. Furthermore, both the immortalized murine NSCs and the human NSCs, despite being unmodified by gene therapy, secreted therapeutic levels of SMPD1 that resulted in a dramatic decrease in neuronal and glial vacuolation and cholesterol levels throughout the brain [71]. Moreover, the migratory and therapeutic potential of human NSCs, isolated directly from the CNS, and those derived from ESCs, has been demonstrated in a mouse of model of Sandhoff disease [62].

Recently, Tamaki et al. [64] also reported studies of transplantation of normal, nontumorogenic, and unmodified

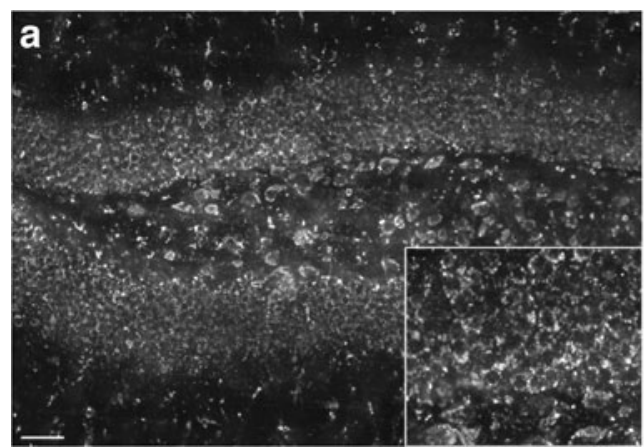

Fig. 3 Efficacy of neural progenitor cells (NPCs) following transplantation into the brains of a mouse model of Niemann Pick A disease. Depletion of sphingomyelin in the hippocampus 4 weeks after bilateral transplantation of gene-modified or unmodified NPCs. The sphingomyelin-specific binding protein lysenin was used to detect this lipid in sections from untreated and treated ASMKO animals. (a, b) Coronal views of the hippocampus showing the marked reduction in fetal human NSCs that had been grown as neurospheres (huCNS-SCs) into the brains of an immunodeficient mouse model of infantile neuronal ceroid lipofuscinosis (INCL). Extensive engraftment and migration of the transplanted cells were noted in the CNS that translated into widespread production of therapeutic levels of the lysosomal enzyme palmitoyl protein thioesterase-1, the enzyme deficient in INCL. Treated mice exhibited significantly reduced neuropathology, a delay in the loss of motor coordination, and an extended survival benefit [64]. This demonstration that early intervention with cellular transplants of huCNS-SCs into the brains of INCL patients might allow for the sustained production of therapeutic levels of palmitoyl protein thioesterase-1 and consequent protection of host neurons was the experimental basis for the human clinical studies with banked huCNS-SCs. The first Food and Drug Administration-authorized human clinical trial using huCNS-SCs in the brains of children with INCL was initiated in 2006 [72, 73]. Results from the phase I clinical trial showed that transplantation of high doses of human NSCs (approximately 1 billion cells) into multiple sites of the brain (8 per patient) was well tolerated. Evidence of regional engraftment and survival of the transplanted cells was also noted. Based on the favorable safety data, a phase $\mathrm{Ib}$ trial in patients with less advanced stages of infantile or late infantile neuronal ceroid lipofuscinosis was initiated in 2010. Recently, this trial was terminated due to the lack of timely patient accrual. A gene therapy trial in 10 children with late infantile neuronal ceroid lipofuscinosis using an adeno-associated virus serotype 2 vector expressing human therapeutic levels of the lysosomal enzyme palmitoyl protein thioesterase- 1 complementary DNA was also purported to be safe and result in a significant reduction in the rate of neurological decline as compared to control subjects [74]. Conceptually, cell transplantation might offer additional

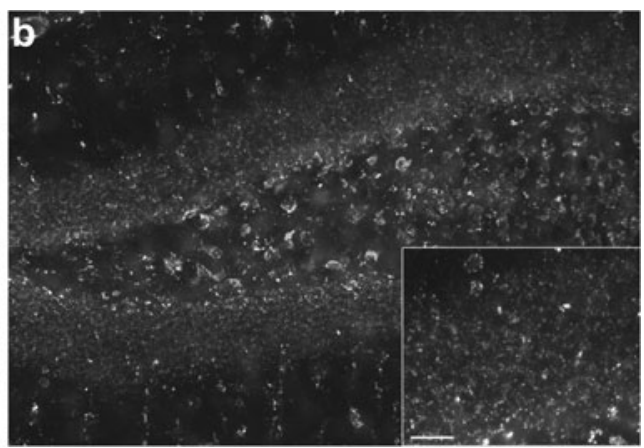

lysenin staining on sections that received (b) gene-modified cells vs (a) unmodified cells. Insets are higher magnification views showing more clearly the marked depletion of sphingomyelin from the cells on sections treated with gene-modified $v s$ unmodified cells. (a, b) Scale bars $=50 \mu \mathrm{m}$; insets scale bars $=25 \mu \mathrm{m}$. (Adapted from Shihabuddin et al. [58]) 


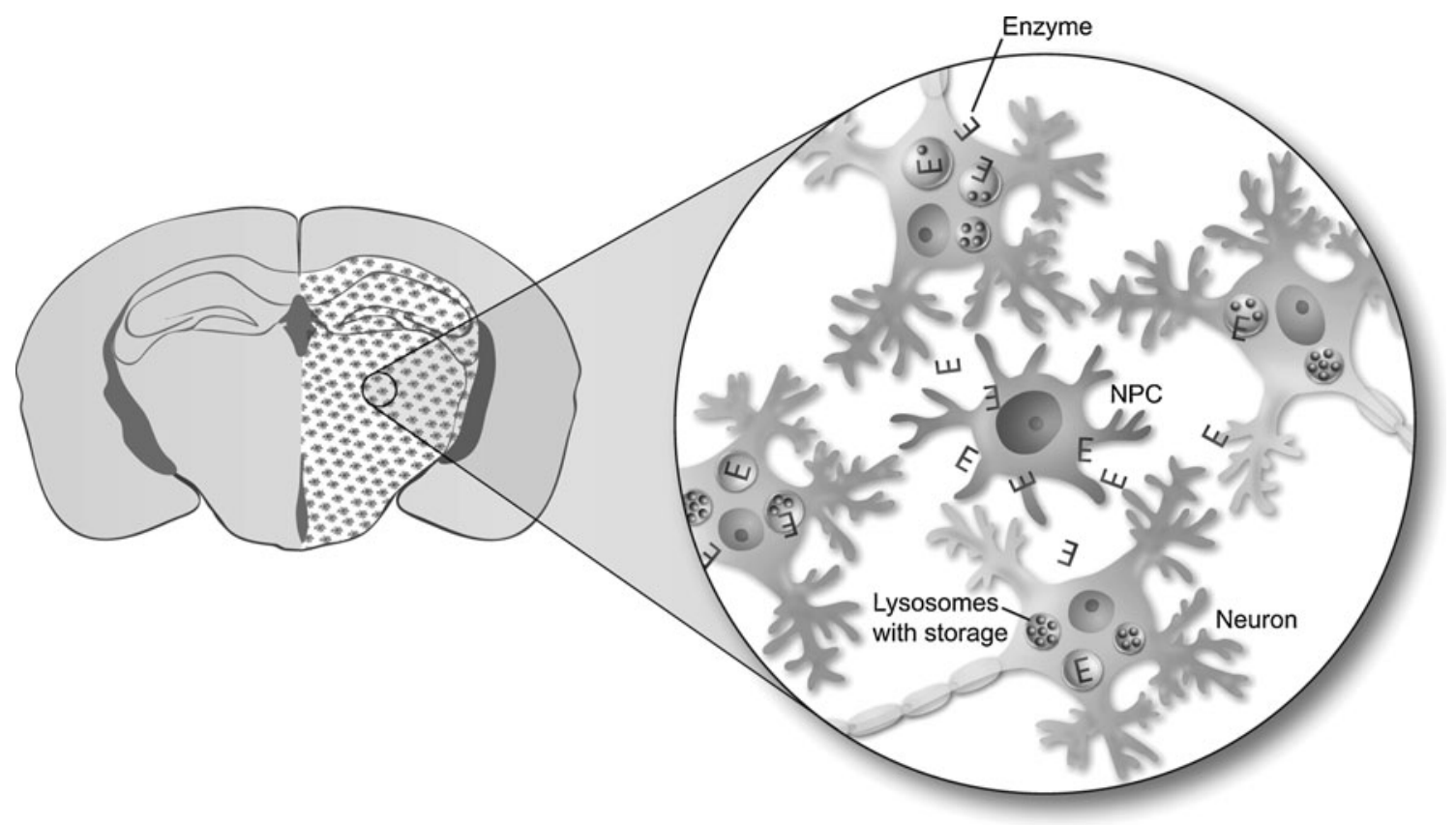

Fig. 4 Schematic diagram showing cross-correction of endogenous neurons in the brain of a mouse model of lysosomal storage diseases (LSDs) following transplantation of neural progenitor cells (NPCs). In the LSDs, the lack of a lysosomal enzyme results in cellular storage buildup within the lysosomes. Following transplantation into the brain

advantages by replacing cells that might have been lost to disease, effecting more global distribution of the enzyme and secreting neuroprotective host factors.

\section{Conclusion}

The potential benefits of cell-mediated therapy for neurometabolic diseases include their ability to confer cell replacement or protection and repair the host nervous system. NSCs possess inherent properties for widespread distribution and the potential for cellular integration following transplantation. As such, they can be used as delivery vehicles for both normally expressed and genetically overexpressed enzymes that are deficient in their hosts [1, 75-77]. For lysosomal storage diseases, a cell-mediated therapeutic approach enlists the ability of transplanted cells to incorporate and produce the enzyme lacking in host cells, thereby preventing excessive lysosomal storage and the death of affected neurons or glia. Recent demonstrations of success in the treatment of several mouse models of LSDs with human neural cells that had been derived by multiple methods support this notion. However, although these studies showed substantial correction of pathology in the mouse brain, these findings will need to be extended to animals with a larger brain to move this therapeutic strategy into the clinic. The generation of NPCs from iPSCs may (shown are the hippocampus and thalamus) of a mouse model of Niemann Pick A disease, the NPCs produced the deficient enzyme (E) for uptake by the neighboring neurons, and uptake of the $\mathrm{E}$ lead to the reduction of waste and neuroprotection. The areas of clearance tightly overlapped with the regional migration of enzyme-producing NPCs provide a large source of donor cells that evade ethical and immune concerns. However, for LSDs patient-derived iPSCs have to be transduced ex-vivo to express the relevant missing enzyme. Potential oncogenic challenges are being addressed using transposon and small molecule induction, as well as by predifferentiation and transdifferentiation. The efficacy and clinical feasibility of iPSC-derived NPC for cell-mediated therapy remain to be determined. Widespread distribution of therapeutic cells in larger brains for clinically relevant use will require the optimization of several factors including: 1) a well-characterized and nontumorigenic human-derived source of stem cells; 2) ex vivo modification of the cells by gene therapy to increase enzyme production, if necessary; 3) determining the number of injection sites and dose of cells to be delivered at each site to ensure effective distribution; 4) the location of the transplant site(s) in the brain for global distribution; and 5) the need for immunosupression for allogenic transplants. Due to the complexity of the neural circuitry, it may be unlikely that stem cell therapy will be able to reverse pathology in brains at the advanced stage of the disease. There is a potential to restore normal function for disability due to ongoing inflammation and cellular dysfunction secondary to lysosomal storage, but neuronal loss and scarring are probably irreversible processes. Thus, it is crucial in neurodegenerative diseases (e.g., with LSDs) to initiate therapy as early as possible for stem cell therapy to have a reasonable 
chance of succeeding. Furthermore, it remains to be determined whether reversal of pathological lesions will be able to arrest the decline in mental development that accompanies most subjects with lysosomal storage disorders. Nevertheless, the encouraging recent preclinical and clinical studies hold promise for the use of neural-derived cell therapy in the treatment of this group of neurometabolic disorders.

Acknowledgments Special thanks to Alison Schroeer, principal medical illustrator, for the artwork in Figs. 1 and 4. LSS and SHC are employees of Genzyme. LSS has been listed as a co-inventor on two filed patents, on the "Cellular therapy for Neurometabolic disorders", W02005016250A2 and W02005016250A3.

Full conflict of interest disclosure is available in the electronic supplementary material for this article.

\section{References}

1. Platt F, Lachmann, RH. Treating lysosomal storage disorders: current practice and future prospects. Biochim Biophys Acta 2009; 1793:737-345.

2. Desnick RJ, Schuchman EH. Enzyme replacement and enhancement therapies: lessons from lysosomal disorders. Nat Rev Genet 2002;3:954-966.

3. Temple S. The development of neural stem cells. Nature 2001;414:112-117.

4. Gage FH. Mammalian neural stem cells. Science 2000;287:1433-1438.

5. Gage FH, Ray J, Fisher LJ. Isolation, characterization, and use of stem cells from the CNS. Annu Rev Neurosci 1995;18:159-192.

6. McKay R. Stem cells in the central nervous system. Science 1997;276:66-71.

7. Weiss S, Reynolds BA, Vescovi AL, Morshead C, Craig CG, van der Kooy D. Is there a neural stem cell in the mammalian forebrain? Trends Neurosci 1996;19:387-393.

8. Pluchino S, Zanotti L, Deleidi M, Martino G. Neural stem cells and their use as therapeutic tool in neurological disorders. Brain Res Brain Res Rev 2005;48:211-219.

9. Goldman S, Windrem M. Cell replacement therapy in neurological disease. Philos Trans R Soc Lond B Biol Sci 2001;361:1463-1475.

10. Vescovi A, Snyder EY. Establishment and properties of neural stem cell clones: plasticity in vitro and in vivo. Brain Pathol 1999;9:569-598.

11. Svendsen C, Caldwell MA, Ostenfeld T. Human neural stem cells: isolation, expansion and transplantation. Brain Pathol 1999;9:499-513.

12. Uchida N, Buck DW, He D, et al. Direct isolation of human central nervous system stem cells. Proc Natl Acad Sci U S A 2000;97:14720-14725.

13. Palmer T, Schwartz PH, Taupin P, Kaspar B, Stein SA, Gage FH. Cell culture. Progenitor cells from human brain after death. Nature 2001;411:42-43.

14. Schwartz P, Bryant PJ, Fuja TJ, Su H, O'Dowd DK, Klassen $\mathrm{H}$. Isolation and characterization of neural progenitor cells from post-mortem human cortex. J Neurosci Res 2003;74:838-851.

15. Weiss S, Dunne C, Hewson J, et al. Multipotent CNS stem cells are present in the adult mammalian spinal cord and ventricular neuroaxis. J Neurosci 1996;16:7599-7609.

16. Gage FH, Coates PW, Palmer TD, et al. Survival and differentiation of adult neuronal progenitor cells transplanted to the adult brain. Proc Natl Acad Sci U S A 1995;92:11879-11883.

17. Kilpatrick T, Bartlett PF. Cloned multipotential precursors from the mouse cerebrum require FGF-2, whereas glial restricted precursors are stimulated with either FGF-2 or EGF. J Neurosci 1995; 15:3653-3661.

18. Gritti A, Parati EA, Cova L, et al. Multipotential stem cells from the adult mouse brain proliferate and self-renew in response to basic fibroblast growth factor. J Neurosci 1996;16:1091-1100.

19. Flax JD, Aurora S, Yang C, et al. Engraftable human neural stem cells respond to developmental cues, replace neurons, and express foreign genes. Nature Biotech 1998;16:1033-1039.

20. Whittemore S, Snyder EY. Physiological relevance and functional potential of central nervous system-derived cell lines. Mol Neurobiol 1996;12:13-38.

21. Ostenfeld T, Caldwell MA, Prowse KR, Linskens MH, Jauniaux E, Svendsen CN. Human neural precursor cells express low levels of telomerase in vitro and show diminishing cell proliferation with extensive axonal outgrowth following transplantation. Exp Neurol 2000;164:215-226.

22. Ray J, Gage FH. Differential properties of adult rat and mouse brain-derived neural stem/progenitor cells. Mol Cell Neurosci 2006;31:560-573.

23. Martinez-Serrano A, Rubio FJ, Navarro B, Bueno C, Villa A. Human neural stem and progenitor cells: in vitro and in vivo properties, and potential for gene therapy and cell replacement in the CNS. Curr Gene Ther 2001;1:279-299.

24. Tamaki S, Eckert K, He D, et al. Engraftment of sorted/expanded human central nervous system stem cells from fetal brain. J Neurosci Res 2002;69:976-986.

25. Thomson JA, Itskovitz-Eldor J, Shapiro SS, et al. Embryonic stem cell lines derived from human blastocysts. Science 1998;282:1145-1147.

26. Ludwig TE, Bergendahl V, Levenstein ME, Yu J, Probasco MD, Thomson JA. Feeder-independent culture of human embryonic stem cells. Nat Methods 2006;3:637-646.

27. Ludwig TE, Levenstein ME, Jones JM, et al. Derivation of human embryonic stem cells in defined conditions. Nat Biotechnol 2006;24:185-187.

28. Conti L, Pollard SM, Gorba T, et al. Niche-independent symmetrical self-renewal of a mammalian tissue stem cell. PLoS Biol 2005;3:1594-1606.

29. McDonald JW, Howard MJ. Repairing the damaged spinal cord: a summary of our early success with embryonic stem cell transplantation and remyelination. Prog Brain Res 2002;137:299 309.

30. Nistor GI, Totoiu MO, Haque N, Carpenter MK, Keirstead HS. Human embryonic stem cells differentiate into oligodendrocytes in high purity and myelinate after spinal cord transplantation. Glia 2005;49:385-396.

31. Vogel G. Cell biology. Ready or not? Human ES cells head toward the clinic. Science 2005;308:1534-1538.

32. Alper J. Geron gets green light for human trial of ES cell-derived product. Nat Biotechnol 2009;27:213-214.

33. Takahashi K, Tanabe K, Ohnuki M, et al. Induction of pluripotent stem cells from adult human fibroblasts by defined factors. Cell 2007;131:861-872.

34. Yu J, Vodyanik MA, Smuga-Otto K, et al. Induced pluripotent stem cell lines derived from human somatic cells. Science 2007;318:1917-1920.

35. Park IH, Zhao R, West JA, et al. Reprogramming of human somatic cells to pluripotency with defined factors. Nature 2008;451:141-146.

36. West MD, Vaziri H. Back to immortality: the restoration of embryonic telomere length during induced pluripotency. Regen Med 2010;5:485-488.

37. Kim J, Efe JA, Zhu S, et al. Direct reprogramming of mouse fibroblasts to neural progenitors. Proc Natl Acad Sci U S A 2011;108:7838-7843.

38. Manohar R, Lagasse E. Transdetermination: a new trend in cellular reprogramming. Mol Ther 2009;17:936-938. 
39. Jiang Y, Henderson D, Blackstad M, Chen A, Miller RF, Verfaillie CM. Neuroectodermal differentiation from mouse multipotent adult progenitor cells. Proc Natl Acad Sci U S A 2003;100:11854-11860.

40. Suzuki H, Taguchi T, Tanaka H, et al. Neurospheres induced from bone marrow stromal cells are multipotent for differentiation into neuron, astrocyte, and oligodendrocyte phenotypes. Biochem Biophys Res Commun 2004;322:918-1022.

41. Krabbe C, Zimmer J, Meyer M. Neural transdifferentiation of mesenchymal stem cells - a critical review. APMIS 2005;113:831-844.

42. Kögler G, Sensken S, Airey JA, et al. A new human somatic stem cell from placental cord blood with intrinsic pluripotent differentiation potential. J Exp Med 2004;200:123-135.

43. Weiss ML, Troyer DL. Stem cells in the umbilical cord. Stem Cell Rev 2006;2:155-162.

44. Tsai MS, Hwang SM, Tsai YL, Cheng FC, Lee, JL, Chang YJ. Clonal amniotic fluid-derived stem cells express characteristics of both mesenchymal and neural stem cells. Biol Reprod 2006;74:545-551.

45. Joannides A, Gaughwin P, Schwiening C, et al. Efficient generation of neural precursors from adult human skin: astrocytes promote neurogenesis from skin-derived stem cells. Lancet 2004;364:172-178.

46. Safford KM, Safford SD, Gimble JM, Shetty, AK, Rice HE. Characterization of neuronal/glial differentiation of murine adipose-derived adult stromal cells. Exp Neurol 2004;187:319328.

47. Brustle O, Spiro AC, Karram K, Choudhary K, Okabe S, McKay RD. In vitro-generated neural precursors participate in mammalian brain development. Proc Natl Acad Sci U S A 1997;94:1480914814.

48. Fricker RA, Carpenter MK, Winkler C, Greco C, Gates MA, Bjorklund A. Site-specific migration and neuronal differentiation of human neural progenitor cells after transplantation in the adult rat brain. J Neurosci 1999; 19:5990-6005.

49. Meikle PJ, Hopwood JJ, Clague AE, Carey WF. Prevalence of lysosomal storage disorders. JAMA 1999;281:249-254.

50. Sly WS, Vogler C. Brain-directed gene therapy for lysosomal storage disease: going well beyond the blood- brain barrier. Proc Natl Acad Sci U S A 2002;99:5760-5762.

51. Porter MT, Fluharty AL, Kihara H. Correction of abnormal cerebroside sulfate metabolism in cultured metachromatic leukodystrophy fibroblasts. Science 1971;172:1263-1265.

52. O'Brien JS, Miller AL, Loverde AW, Veath ML. Sanfilippo disease type B: enzyme replacement and metabolic correction in cultured fibroblasts. Science 1973;181:753-755.

53. Neufeld EF. Enzyme replacement therapy. In: Platt FM, Walkely SU, ed. Lysosomal disorders of the brain. Oxford: Oxford University Press, 2004:327-338.

54. Taylor RM, Wolfe JH. Decreased lysosomal storage in the adult MPS VII mouse brain in the vicinity of grafts of retroviral vectorcorrected fibroblasts secreting high levels of beta-glucuronidase. Nat Med 1997;3:771-774.

55. Jin HK, Carter JE, Huntley GW, Schuchman EH. Intracerebral transplantation of mesenchymal stem cells into acid sphingomyelinase-deficient mice delays the onset of neurological abnormalities and extends their life span. J Clin Invest 2002;109:11831191.

56. Buchet D, Serguera C, Zennou V, Charneau P, Mallet J. Long-term expression of beta-glucuronidase by genetically modified human neural progenitor cells grafted into the mouse central nervous system. Mol Cell Neurosci 2002;19:389-401.

57. Meng XL, Shen JS, Ohashi T, Maeda H, Kim SU, Eto Y. Brain transplantation of genetically engineered human neural stem cells globally corrects brain lesions in the mucopolysaccharidosis type VII mouse. J Neurosci Res 2003;74:266-277.
58. Shihabuddin LS, Numan S, Huff MR, et al. Intracerebral transplantation of adult mouse neural progenitor cells into the Niemann-Pick-A mouse leads to a marked decrease in lysosomal storage pathology. J Neurosci 2004;24:1064210651.

59. Biffi A, De Palma M, Quattrini A, et al. Correction of metachromatic leukodystrophy in the mouse model by transplantation of genetically modified hematopoietic stem cells. J Clin Invest 2004;113:1118-1129.

60. Snyder EY, Taylor RM, Wolfe JH. Neural progenitor cell engraftment corrects lysosomal storage throughout the MPS VII mouse brain. Nature 1995;374:367-370.

61. Lacorazza HD, Flax JD, Snyder EY, Jendoubi M. Expression of human beta-hexosaminidase alpha-subunit gene (the gene defect of Tay-Sachs disease) in mouse brains upon engraftment of transduced progenitor cells. Nat Med 1996;2:424-429.

62. Lee JP, Jeyakumar M, Gonzalez R, et al. Stem cells act through multiple mechanisms to benefit mice with neurodegenerative metabolic disease. Nat Med 2007;13:439-447.

63. Jeyakumar M, Lee JP, Sibson NR, et al. Neural stem cell transplantation benefits a monogenic neurometabolic disorder during the symptomatic phase of disease. Stem Cells 2009;27:23622370.

64. Tamaki SJ, Jacobs Y, Dohse M, et al. Neuroprotection of host cells by human central nervous system stem cells in a mouse model of infantile neuronal ceroid lipofuscinosis. Cell Stem Cell 2009;5:310-319.

65. Leventhal A, Chen W, Tall AR, Tabas I. Acid sphingomyelinasedeficient macrophages have defective cholesterol trafficking and efflux. J Biol Chem 2001;276:44976-44983.

66. Slotte J. Sphingomyelin-cholesterol interactions in biological and model membranes. Chem Phys Lipids 1999;102:13-27.

67. Viana M, Giugliani R, Leite VH, et al. Very low levels of high density lipoprotein cholesterol in four sibs of a family with nonneuropathic Niemann-Pick disease and sea-blue histiocytosis. J Med Genet 1990;27:499-504.

68. Sarna J, Miranda SR, Schuchman EH, Hawkes R. Patterned cerebellar Purkinje cell death in a transgenic mouse model of Niemann Pick type A/B disease. Eur J Neurosci 2001;13:18731880.

69. Yamaji A, Sekizawa Y, Emoto K, et al. Lysenin, a novel sphingomyelin-specific binding protein. J Biol Chem 1998;273:5300-5306.

70. Leinekugel P, Michel S, Conzelmann E, Sandhoff K. Quantitative correlation between the residual activity of beta-hexosaminidase A and arylsulfatase A and the severity of the resulting lysosomal storage disease. Hum Genet 1992;88:513-523.

71. Sidman R, Li J, Stewart GR, et al. Injection of mouse and human neural stem cells into neonatal Niemann-Pick A model mice. Brain Res 2006;1140:195-204.

72. Hobert J, Dawson G. Neuronal ceroid lipofuscinoses therapeutic strategies: past, present and future. Biochim Biophys Acta 2006;1762:945-953.

73. Taupin P. HuCNS-SC (StemCells). Curr Opin Mol Ther 2006;8:156-163.

74. Worgall S, Sondhi D, Hackett NR, et al. Treatment of late infantile neuronal ceroid lipofuscinosis by CNS administration of a serotype 2 adeno-associated virus expressing CLN2 cDNA. Hum Gene Ther 2008;19:463-374.

75. Kim SU, de Vellis, J. Stem cell-based cell therapy in neurological diseases: a review. J Neurosci Res 2009;87:2183-2200.

76. Schwartz PH, Brick DJ. Stem cell therapies for the lysosomal storage diseases - the quintessential neurodegenerative diseases. Curr Stem Cell Res Ther 2008;3:88-98.

77. Enns GM, Huhn, SL. Central nervous system therapy for lysosomal storage disorders. Neurosurg Focus 2008;24:1-12. 